\title{
SMPD1 variants do not have a major role in REM sleep behavior disorder
}

Uladzislau Rudakou1,2, Naomi C. Futhey2, Lynne Krohn1,2, Jennifer A. Ruskey2,3, Karl Heilbron4, Paul Cannon4, The 23andMe Research Team4, Armaghan Alam2, Isabelle Arnulf5, Michele T.M. Hu6, 7, Jacques Y. Montplaisir8,9, Jean-François Gagnon8,10, Alex Desautels8,11, Yves Dauvilliers12, Marco Toffoli13,14, Gian Luigi Gigli15,16, Mariarosaria Valente13,15, Birgit Högl17, Ambra Stefani17, Evi Holzknecht17, Karel Sonka18, David Kemlink18, Wolfang Oertel19, Annette Janzen19, Giuseppe Plazzi20,21, Elena Antelmi20,21, Michela Figorilli22, Monica Puligheddu22, Brit Mollenhauer23,24, Claudia Trenkwalder23,24, Friederike SixelDöring23,19, Valérie Cochen De Cock25,26, Christelle Charley Monaca27, Anna Heidbreder28, Luigi FeriniStrambi29, Femke Dijkstra30,31, Mineke Viaene 30,31, Abril Beatriz32, Bradley F. Boeve33, Ronald B. Postuma2,3,34, Guy A. Rouleau1,2,3, Ziv Gan-Or1,2,3

\section{Affiliations:}

1.Department of Human Genetics, McGill University, Montréal, QC, Canada; 2. Montreal Neurological Institute, McGill University, Montréal, QC, Canada; 3. Department of Neurology and Neurosurgery, McGill University, Montréal, QC, Canada; 4. 23andMe, Inc., 223 N Mathilda Avenue, Sunnyvale, California 94086 USA; 5.Sleep Disorders Unit, Pitié Salpêtrière Hospital, Centre de Recherche de l'Institut du Cerveau et de la Moelle Epinière and Sorbonne University, Paris, France; 6. Oxford Parkinson's Disease Centre (OPDC), University of Oxford, Oxford, United Kingdom; 7. Nuffield Department of Clinical Neurosciences, University of Oxford, Oxford, United Kingdom; 8. Centre d'Études Avancées en Médecine du Sommeil, Hôpital du Sacré-Cœur de Montréal, Montréal, QC, Canada; 9. Department of Psychiatry, Université de Montréal, Montréal, QC, Canada; 10. Department of Psychology, Université du Québec à Montréal, Montréal, QC, Canada; 11. Department of Neurosciences, Université de Montréal, Montréal, QC, H3T 1J4, Canada; 12. National Reference Center for Narcolepsy, Sleep Unit, Department of Neurology, Gui-de-Chauliac Hospital, CHU Montpellier, University of Montpellier, Inserm U1061, Montpellier, France; 13. Department of Medicine (DAME), University of Udine, Udine, Italy; 14. Department of Clinical and Movement Neurosciences, UCL Queen Square Institute of Neurology, London, UK; 15. Clinical Neurology Unit, Department of Neurosciences, University Hospital of Udine, Udine, Italy; 16. DMIF, University of Udine, Udine, Italy; 17. Sleep Disorders Clinic, Department of Neurology, Medical University of Innsbruck, Innsbruck, Austria; 18. Department of Neurology and Centre of Clinical Neuroscience, Charles University, First Faculty of Medicine and General University Hospital, Prague, Czech Republic; 19. Department of Neurology, Philipps University, Marburg, Germany; 20. Department of Biomedical and Neuromotor Sciences (DIBINEM), Alma Mater Studiorum, University of Bologna, Bologna, Italy; 21. IRCCS, Institute of Neurological Sciences of Bologna, Bologna, Italy; 22. Department of Medical Sciences and Public Health, Sleep Disorder Research Center, University of Cagliari, Cagliari, Italy; 23. Paracelsus-Elena-Klinik, Kassel, Germany; 24. Department of Neurology, University Medical Centre Goettingen, Goettingen, Germany; 25. Sleep and Neurology Unit, Beau Soleil Clinic, Montpellier, France; 26. EuroMov, University of Montpellier, Montpellier, France; 27. University Lille North of France, Department of Clinical Neurophysiology and Sleep Center, CHU Lille, Lille, France; 28. Department of Sleep Medicine and Neuromuscular Disorders, University of Muenster, Germany; 29. Department of Neurological Sciences, Università Vita-Salute San Raffaele, Milan, Italy; 30. Laboratory for Sleep Disorders, St. Dimpna Regional Hospital, Geel, Belgium; 31. Department of Neurology, St. Dimpna Regional Hospital, Geel, Belgium; 32. Sleep disorder Unit, Carémeau Hospital, University Hospital of 
Nîmes, France; 33. Department of Neurology, Mayo Clinic, Rochester, MN, USA; 34. Centre d'Études Avancées en Médecine du Sommeil, Hôpital du Sacré-Coeur de Montréal, Montréal, QC, Canada.

\title{
Corresponding author:
}

\author{
Ziv Gan-Or \\ Montreal Neurological Institute, \\ McGill University \\ 1033 Pine Avenue, West, \\ Ludmer Pavilion, room 312 \\ Montreal, QC, H3A 1A1, \\ Phone: +1-514-398-5845 \\ e-mail: ziv.gan-or@mcgill.ca
}

Keywords: REM-sleep behavior disorder (RBD), sphingomyelin phosphodiesterase 1, SMPD1, association study 


\section{Abstract}

Mutations in the sphingomyelin phosphodiesterase 1 (SMPD1) gene were reported to be associated with Parkinson disease (PD) and dementia with Lewy bodies (DLB). The majority of patients with isolated rapid eye movement sleep behavior disorder (iRBD) develop PD or DLB later in life, suggesting that iRBD is a prodromal phase of these two conditions. In the current study we aimed to evaluate the role of SMPDI variants in iRBD. SMPDI and its untranslated regions were sequenced using targeted next-generation sequencing in 959 iRBD patients and 1,287 controls from European descent. Logistic regression adjusted for sex and age showed no significant associations with two common variants and iRBD (rs1050239 and rs8164). The frequency of all rare nonsynonymous SMPD1 variants (minor allele frequency <1\%) was found to be twice as high in cases than in controls $(1.46 \%$ vs. $0.70 \%$, Fisher's exact test $p=0.09)$ but there was no statistically significant burden $(p=0.64)$. Our study reports no statistically significant association of $S M P D 1$ variants and $\mathrm{RBD}$. It is hence unlikely that $S M P D 1$ plays a major role in $\mathrm{RBD}$. 


\section{Introduction}

The sphingomyelin phosphodiesterase 1 (SMPD1) gene on chromosome 11 encodes the lysosomal enzyme acid sphingomyelinase, which converts sphingomyelin into ceramide. Homozygous or compound heterozygous mutations in SMPD1 may cause Niemann-Pick disease type A (NPA) or type B (NPB), lysosomal storage disorders characterized by acid sphingomyelinase (ASM) deficiency and accumulation of sphingomyelin (Schuchman and Desnick, 2017). Sphingomyelin is a major component of both cell membranes and the myelin sheath that surrounds axons in the nervous system (Jana and Pahan, 2010; Quinn, 2014). In recent years, heterozygous SMPDI variants have been reported as risk factors for PD (Alcalay et al., 2019; Dagan et al., 2015; Foo et al., 2013; Gan-Or et al., 2013; Mao et al., 2017), and have been suggested to be associated with DLB (Clark et al., 2015).

Rapid-eye-movement (REM) sleep behavior disorder (RBD) is characterized by lack of motor inhibition and dream enactment during REM sleep (St Louis et al., 2017). Accumulating evidence suggests that isolated RBD (iRBD) is a prodromal synucleinopathy, since individuals with isolated RBD are very likely to convert to PD, DLB, or multiple system atrophy (MSA) (Postuma et al., 2019). In order to examine the genetic basis of iRBD and its conversion, recent studies have examined whether PD- or DLB-associated genes are also associated with $\mathrm{RBBD}$ and whether they affect its conversion. It was demonstrated that while some genes such as GBA (Krohn et al., 2019b), TMEM175 (Krohn et al., 2019a) and SNCA (Krohn et al., 2019c) are associated with iRBD, other PD and DLB genes such as LRRK2 (Ouled Amar Bencheikh et al., 2018), APOE (Gan-Or et al., 2017) and MAPT (Li et al., 2018) are not. However, the association between SMPDI and iRBD has not been investigated.

Therefore, in the current study we aimed to examine whether rare and common SMPDI variants are associated with iRBD. The entire coding regions, the exon-intron boundaries and the 5' and 3' untranslated regions of SMPD1 were sequenced in a large cohort of iRBD patients and controls, followed by different analyses to test for association of specific variants or burden of multiple variants in iRBD. 


\section{Methods}

\subsection{Study Population}

A total of 2,246 subjects, composed of 959 unrelated iRBD patients and 1,287 controls, were included in the study. All subjects were of European descent, confirmed by principal component analysis of genotype data that were available for these patients, as we have previously reported (Krohn et al., 2019a). Patients with iRBD had a mean age of $67.9 \pm 9.2$ (data on age were missing for 7 patients) with $80.7 \%$ males (data missing for 31 patients). Controls were all over the age of 40, with a mean age of $59.2 \pm 9.3$ and $53.7 \%$ males. RBD was diagnosed with video-polysomnography according to the International Classification of Sleep Disorders (ICSD), version 2 or 3 (Hogl and Stefani, 2017). All participants signed an informed consent form before entering the study, and the institutional review boards approved the study protocols.

To further investigate one variant in RBD, we examined genome-wide association study (GWAS) summary statistics provided by 23andMe from 1,782 PD cases with probable RBD (PD+pRBD) and 131,250 ageand sex-matched controls. In this cohort, probable RBD was assessed using the RBD1Q questionnaire which has high sensitivity and specificity in PD patients (Postuma et al., 2012). Cases and controls were genotyped on Illumina genotyping platforms, underwent standard GWAS quality control procedures and were imputed and filtered for imputation quality score $>0.80$. All individuals included in the analyses provided informed consent and answered surveys online according to the 23andMe human subject protocol, which was reviewed and approved by Ethical \& Independent Review Services, a private institutional review board (http://www.eandireview.com). The full protocol is available upon request.

\subsection{SMPD1 Sequencing}

Coding sequence and regulatory regions of SMPD1 were targeted using molecular inversion probes (MIPs), designed as previously described (O'Roak et al., 2012). MIPs were selected based on their predicted coverage, quality and overlap, and capture was done as previously reported (Ross et al., 2016). 
Supplementary Table 1 includes all the MIPs used to sequence SMPD1, and the full protocol is available upon request. The library was sequenced using Illumina HiSeq 2500 or 4000 platform at the McGill University and Genome Quebec Innovation Centre. Sequence processing was performed by: BurrowsWheeler Aligner for alignment to the human reference genome (hg19) (Li and Durbin, 2009), the Genome Analysis Toolkit (GATK, v3.8) for post-alignment cleanup and variant calling (McKenna et al., 2010), and ANNOVAR for annotation (Wang et al., 2010). Frequency data on each SMPDl variant was extracted from the Genome Aggregation Database (gnomAD) (Lek et al., 2016). Pathogenicity of variants was examined with ClinVar (https://www.ncbi.nlm.nih.gov/clinvar/), especially with respect to Niemann-Pick's disease. Validations of the rare variants was performed with Sanger sequencing. Supplementary Table 2 details the primers used for validations, and the full protocol is available upon request.

\subsection{Quality Control}

Quality control (QC) filtration was performed using GATK v3.8 and PLINK software v1.9 (Purcell et al., 2007). Samples with average genotyping rate of less than $90 \%$ were excluded. We excluded variants based on the following criteria: coverage quality score (GQ) below 30, minimum depth of coverage which was set to $15 \mathrm{x}$ for common variants and 30x for rare variants, genotyping rate of less than $90 \%$, deviation from the Hardy-Weinberg equilibrium set at $p=0.001$, missingness difference between patients and controls set at $p=0.05$ and adjusted by Bonferroni correction.

\subsection{Statistical Analysis}

The association between common SMPDI variants and $\mathrm{RBBD}$ was tested using a logistic regression using PLINK v1.9, with the disease status (case or control) as a dependent variable, adjusted for age and sex. To analyze rare variants as defined by a minor allele frequency (MAF) of less than 0.01 , optimized Sequence Kernel Association Test (SKAT-O, R package) was performed (Lee et al., 2012). 


\section{Results}

The average coverage of SMPD1 was 393x, with $96 \%$ of the nucleotides covered at $>20 x$, and $85 \%$ covered at $>50 x$. Table 1 details the frequencies of two common variants, rs 1050239 and rs8164, in iRBD patients and controls. Both variants were not associated with iRBD ( $p=0.48$ and $p=0.55$, respectively, Table 1$)$. Table 2 details rare nonsynonymous and indel variants (no splice or stop variants were identified) with MAF $<0.01$ in iRBD patients and controls. The frequency of rare variants in iRBD patients was double than their frequency in controls, but the difference was not statistically significant $(1.46 \%$ vs. $0.70 \%$ respectively, Fisher's exact test $p=0.09$ ). There was no statistically significant burden of rare variants in SMPDI in iRBD (SKAT-O, $p=0.64$ ). The difference in frequency of rare variants between RBD patients and control was mainly driven by the p.Ala487Val. This variant was previously nominally associated with PD, albeit non-significant after correction for multiple comparisons (Alcalay et al., 2019), and it was found in $8(0.83 \%)$ of iRBD patients and in $3(0.23 \%)$ of controls $(\mathrm{OR}=3.6,95 \% \mathrm{CI}=0.95-13.6, p=0.06)$. However, since the control population in the current study includes controls that were used in the previous study, it is possible that by chance the frequency of this variant in our control population is low. To test this possibility, we examined data from 23andMe, comparing 1,782 PD+pRBD patients and 131,250 controls. The allele frequency of the p.Ala487Val was $0.53 \%$ in patients and $0.46 \%$ in controls, suggesting a lack of association between this variant and $\mathrm{pRBD}$ in $\mathrm{PD}$ patients $(\mathrm{OR}=1.13,95 \% \mathrm{CI}=0.68-1.88, p=0.64)$, and indeed suggesting that the frequency in our control population may be low by chance. 


\section{Discussion}

In the current study we fully sequenced SMPD1 in 959 iRBD patients and 1,287 controls and identified 8 rare SMPDI variants $(\mathrm{MAF}<0.01)$, and 2 common variants $(\mathrm{MAF}>0.01)$. We found no strong evidence for an association of rare or common SMPDI variants with iRBD. In a previous large study of PD, the frequencies of SMPD1 mutations in PD patients and controls of Ashkenazi Jewish (AJ) origin were 1.7\% and $0.4 \%$, respectively (Alcalay et al., 2019). With our sample size, we had $>80 \%$ power to detect such differences between patients and controls at $p<0.05$. However, since our population is less homogeneous than the AJ population, we cannot rule out that rare SMPDI variants or variants with small effect size contribute to $\mathrm{RBDD}$, and larger studies will be required in the future to conclusively determine the role of SMPDI in iRBD.

Rare SMPDI variants were more frequent in cases compared to controls, yet without statistical significance. The increased frequency in patients was driven by the p.Ala487Val variant, which was previously nominally associated with PD, albeit non-significant after correction for multiple comparisons. However, the European control group that was used in the current study included the European controls used in the previous study. Therefore, it is possible that the reduced frequency in the control population is due to chance and drives the apparent association reported in PD and the differences between RBD and controls reported here. To further examine whether p.Ala487Val is associated with RBD, we examined data from 23andMe comparing PD+pRBD patients and controls, which yielded statistically non-significant results. These results may suggest that this variant is not associated with RBD, and may further imply that the previously reported association of this specific variant with PD was also due to chance. However, we cannot rule out a minor role for this variant that requires larger cohorts and statistical power to detect. It is important to note that while this variant is likely not pathogenic in Niemann-Pick disease (Zampieri et al., 2016), it was associated with reduced acid sphingomyelinase activity in dried blood spots from PD patients and controls (Alcalay et al., 2019). 
In previous studies, NPA-causing mutations, such as p.L302P (also called p.L304P) and p.fsP330 (also called p.F333Sfs*52 or c.996delC), have consistently been associated with PD (Alcalay et al., 2019; Dagan et al., 2015; Gan-Or et al., 2013). In the current study we did not identify any mutation that causes NPA, but we did identify one mutation, p.Arg610del (previously reported as p.Arg608del or DeltaR608) (Wasserstein and Schuchman, 1993; Zampieri et al., 2016), which causes NPB when inherited in the homozygous or compound heterozygous state with other mutations (Hollak et al., 2012; Jones et al., 2008; Rodriguez-Pascau et al., 2009; Vanier et al., 1993), found in one patient and one control. Therefore, we cannot rule out that rare, thus-far undetected NPA-associated rare variants are associated with iRBD.

Our study has several limitations. Although we analyzed more than 2200 individuals, due to the rarity of NPA-causing mutations we may be underpowered to detect an association of rare SMPD1 mutations with RBD. Therefore, larger studies will be needed to better define the role of SMPD1 variants in RBD. Another limitation is that there were differences in age and sex between RBD patients and controls. In the case of rare variants, these differences are not likely to have an effect, and in analyzing common variants we have adjusted for sex and age.

In conclusion, despite the reported association of SMPDI variants with PD and DLB, our data does not support a major role for SMPD1 variants in RBD, yet additional, larger studies are required to conclusively rule out this possibility.

\section{Acknowledgements}

We thank the patients and control subjects for their participation in this study. This work was financially supported by the Michael J. Fox Foundation, the Canadian Consortium on Neurodegeneration in Aging (CCNA), Parkinson Canada, and the Canada First Research Excellence Fund (CFREF), awarded to McGill University for the Healthy Brains for Healthy Lives (HBHL) program. JFG holds a Canada Research Chair 
in Cognitive Decline in Pathological Aging. GAR holds a Canada Research Chair in Genetics of the Nervous System and the Wilder Penfield Chair in Neurosciences. WO is Hertie Senior Research Professor, supported by the Charitable Hertie Foundation, Frankfurt/Main, Germany. EAF holds a Canada Research Chair (Tier 1) in Parkinson Disease. ZGO is supported by the Fonds de recherche du Québec - Santé (FRQ-

S) Chercheurs-boursiers award, and is a Parkinson's Disease Canada New Investigator awardee. We thank Daniel Rochefort, Helene Catoire and Vessela Zaharieva for their assistance. Members of the 23andMe Research Team: Michelle Agee, Adam Auton, Robert K. Bell, Katarzyna Bryc, Sarah L. Elson, Pierre Fontanillas, Nicholas A. Furlotte, Barry Hicks, David A. Hinds, Karen E. Huber, Ethan M. Jewett, Yunxuan Jiang, Aaron Kleinman, Keng-Han Lin, Nadia K. Litterman, Matthew H. McIntyre, Kimberly F. McManus, Joanna L. Mountain, Elizabeth S. Noblin, Carrie A.M. Northover, Steven J. Pitts, G. David Poznik, Janie F. Shelton, Suyash Shringarpure, Chao Tian, Joyce Y. Tung, Vladimir Vacic, and Xin Wang

\section{Conflicts of Interest}

$\mathrm{KH}, \mathrm{PC}$, and members of the 23andMe Research Team are employees of 23andMe, Inc., and hold stock or stock options in 23andMe. ZGO has received consultancy fees from Idorsia, Denali, Lysosomal Therapeutics Inc. (LTI), Ono Therapeutics, Prevail Therapeutics, Inceptions Sciences (now Ventus) and Deerfield.

\section{References}

Alcalay, R.N., Mallett, V., Vanderperre, B., Tavassoly, O., Dauvilliers, Y., Wu, R.Y.J., Ruskey, J.A., Leblond, C.S., Ambalavanan, A., Laurent, S.B., Spiegelman, D., Dionne-Laporte, A., Liong, C., Levy, O.A., Fahn, S., Waters, C., Kuo, S.H., Chung, W.K., Ford, B., Marder, K.S., Kang, U.J., Hassin-Baer, S., Greenbaum, L., Trempe, J.F., Wolf, P., Oliva, P., Zhang, X.K., Clark, L.N., Langlois, M., Dion, P.A., Fon, E.A., Dupre, N., Rouleau, 
G.A., Gan-Or, Z., 2019. SMPD1 mutations, activity, and alpha-synuclein accumulation in Parkinson's disease. Mov Disord. 34(4), 526-535.

Clark, L.N., Chan, R., Cheng, R., Liu, X., Park, N., Parmalee, N., Kisselev, S., Cortes, E., Torres, P.A., Pastores, G.M., Vonsattel, J.P., Alcalay, R., Marder, K., Honig, L.L., Fahn, S., Mayeux, R., Shelanski, M., Di Paolo, G., Lee, J.H., 2015. Gene-wise association of variants in four lysosomal storage disorder genes in neuropathologically confirmed Lewy body disease. PLoS One 10(5), e0125204.

Dagan, E., Schlesinger, I., Ayoub, M., Mory, A., Nassar, M., Kurolap, A., Peretz-Aharon, J., Gershoni-Baruch, R., 2015. The contribution of Niemann-Pick SMPD1 mutations to Parkinson disease in Ashkenazi Jews. Parkinsonism Relat Disord. 21(9), 1067-1071.

Foo, J.N., Liany, H., Bei, J.X., Yu, X.Q., Liu, J., Au, W.L., Prakash, K.M., Tan, L.C., Tan, E.K., 2013. Rare lysosomal enzyme gene SMPD1 variant (p.R591C) associates with Parkinson's disease. Neurobiol Aging 34(12), 2890 e2813-2895.

Gan-Or, Z., Montplaisir, J.Y., Ross, J.P., Poirier, J., Warby, S.C., Arnulf, I., Strong, S., Dauvilliers, Y., Leblond, C.S., Hu, M.T.M., Hogl, B., Stefani, A., Monaca, C.C., De Cock, V.C., Boivin, M., Ferini-Strambi, L., Plazzi, G., Antelmi, E., Young, P., Heidbreder, A., Barber, T.R., Evetts, S.G., Rolinski, M., Dion, P.A., Desautels, A., Gagnon, J.F., Dupre, N., Postuma, R.B., Rouleau, G.A., 2017. The dementia-associated APOE epsilon4 allele is not associated with rapid eye movement sleep behavior disorder. Neurobiol Aging 49, 218 e213-218 e215.

Gan-Or, Z., Ozelius, L.J., Bar-Shira, A., Saunders-Pullman, R., Mirelman, A., Kornreich, R., Gana-Weisz, M., Raymond, D., Rozenkrantz, L., Deik, A., Gurevich, T., Gross, S.J., Schreiber-Agus, N., Giladi, N., Bressman, S.B., Orr-Urtreger, A., 2013. The p.L302P mutation in the lysosomal enzyme gene SMPD1 is a risk factor for Parkinson disease. Neurology 80(17), 1606-1610.

Hogl, B., Stefani, A., 2017. REM sleep behavior disorder (RBD): Update on diagnosis and treatment. Somnologie (Berl) 21(Suppl 1), 1-8.

Hollak, C.E., de Sonnaville, E.S., Cassiman, D., Linthorst, G.E., Groener, J.E., Morava, E., Wevers, R.A., Mannens, M., Aerts, J.M., Meersseman, W., Akkerman, E., NiezenKoning, K.E., Mulder, M.F., Visser, G., Wijburg, F.A., Lefeber, D., Poorthuis, B.J., 2012. Acid sphingomyelinase (Asm) deficiency patients in The Netherlands and Belgium: disease spectrum and natural course in attenuated patients. Mol Genet Metab. 107(3), 526-533.

Jana, A., Pahan, K., 2010. Sphingolipids in multiple sclerosis. Neuromolecular Med. 12(4), 351361. 
Jones, I., He, X., Katouzian, F., Darroch, P.I., Schuchman, E.H., 2008. Characterization of common SMPD1 mutations causing types A and B Niemann-Pick disease and generation of mutation-specific mouse models. Mol Genet Metab. 95(3), 152-162.

Krohn, L., Ozturk, T.N., Vanderperre, B., Ouled Amar Bencheikh, B., Ruskey, J.A., Laurent, S.B., Spiegelman, D., Postuma, R.B., Arnulf, I., Hu, M.T.M., Dauvilliers, Y., Hogl, B., Stefani, A., Monaca, C.C., Plazzi, G., Antelmi, E., Ferini-Strambi, L., Heidbreder, A., Rudakou, U., Cochen De Cock, V., Young, P., Wolf, P., Oliva, P., Zhang, X.K., Greenbaum, L., Liong, C., Gagnon, J.F., Desautels, A., Hassin-Baer, S., Montplaisir, J.Y., Dupre, N., Rouleau, G.A., Fon, E.A., Trempe, J.F., Lamoureux, G., Alcalay, R.N., Gan-Or, Z., 2019a. Genetic, Structural, and Functional Evidence Link TMEM175 to Synucleinopathies. Ann Neurol. 87(1):139-153.

Krohn, L., Ruskey, J.A., Rudakou, U., Leveille, E., Asayesh, F., Hu, M.T.M., Arnulf, I., Dauvilliers, Y., Högl, B., Stefani, A., Monaca, C.C., Plazzi, G., Antelmi, E., FeriniStrambi, L., Heidbreder, A., Boeve, B.F., Espay, A.J., Cochen de Cock, V., Mollenhauer, B., Sixel-Doering, F., Trenkwalder, C., Sonka, K., Kemlink, D., Figorilli, M., Puligheddu, M., Dijkstra, F., Viaene, M., Oertel, W., Toffoli, M., Gigli, G.L., Valente, M., Gagnon, J.F., Desautels, A., Montplaisir, J.Y., Postuma, R.B., Rouleau, G., Gan-Or, Z., 2019b. GBA variants in REM sleep behavior disorder: a multicenter study. medRxiv, DOI: https://doi.org/10.1101/2020.01.21.20018101

Krohn, L., Wu, R.Y.J., Heilbron, K., Ruskey, J.A., Laurent, S.B., Blauwendraat, C., Alam, A., Arnulf, I., Hu, M.T.M., Dauvilliers, Y., Hogl, B., Toft, M., Bjørnarå, K.A., Stefani, A., Holzknecht, E., Monaca, C.C., Beatriz, A., Plazzi, G., Antelmi, E., Ferini-Strambi, L., Young, P., Heidbreder, A., Cochen de Cock, V., Mollenhauer, B., Sixel-Doering, F., Trenkwalder, C., Sonka, K., Kemlink, D., Figorilli, M., Puligheddu, M., Dijkstra, F., Viaene, M., Oertel, W., Toffoli, G., Gigli, G.L., Valente, M., Gagnon, J.F., Nalls, M.A., Singleton, A.B., Team, a.R., Desautels, A., Montplaisir, J.Y., Cannon, P., Ross, O.A., Boeve, B.F., Dupré, N., Fon, E.A., Postuma, R.B., Pihlstrøm, L., Rouleau, G., Gan-Or, Z., 2020. Fine-mapping of SNCA in REM sleep behavior disorder and overt synucleinopathies. Ann Neurol. DOI: 10.1002/ana.25687. [Epub ahead of print]

Lee, S., Emond, M.J., Bamshad, M.J., Barnes, K.C., Rieder, M.J., Nickerson, D.A., Team, N.G.E.S.P.-E.L.P., Christiani, D.C., Wurfel, M.M., Lin, X., 2012. Optimal unified approach for rare-variant association testing with application to small-sample casecontrol whole-exome sequencing studies. Am J Hum Genet. 91(2), 224-237.

Lek, M., Karczewski, K.J., Minikel, E.V., Samocha, K.E., Banks, E., Fennell, T., O'DonnellLuria, A.H., Ware, J.S., Hill, A.J., Cummings, B.B., Tukiainen, T., Birnbaum, D.P., Kosmicki, J.A., Duncan, L.E., Estrada, K., Zhao, F., Zou, J., Pierce-Hoffman, E., Berghout, J., Cooper, D.N., Deflaux, N., DePristo, M., Do, R., Flannick, J., Fromer, M., Gauthier, L., Goldstein, J., Gupta, N., Howrigan, D., Kiezun, A., Kurki, M.I., Moonshine, A.L., Natarajan, P., Orozco, L., Peloso, G.M., Poplin, R., Rivas, M.A., Ruano-Rubio, V., Rose, S.A., Ruderfer, D.M., Shakir, K., Stenson, P.D., Stevens, C., Thomas, B.P., Tiao, 
G., Tusie-Luna, M.T., Weisburd, B., Won, H.H., Yu, D., Altshuler, D.M., Ardissino, D., Boehnke, M., Danesh, J., Donnelly, S., Elosua, R., Florez, J.C., Gabriel, S.B., Getz, G., Glatt, S.J., Hultman, C.M., Kathiresan, S., Laakso, M., McCarroll, S., McCarthy, M.I., McGovern, D., McPherson, R., Neale, B.M., Palotie, A., Purcell, S.M., Saleheen, D., Scharf, J.M., Sklar, P., Sullivan, P.F., Tuomilehto, J., Tsuang, M.T., Watkins, H.C., Wilson, J.G., Daly, M.J., MacArthur, D.G., Exome Aggregation, C., 2016. Analysis of protein-coding genetic variation in 60,706 humans. Nature 536(7616), 285-291.

Li, H., Durbin, R., 2009. Fast and accurate short read alignment with Burrows-Wheeler transform. Bioinformatics 25(14), 1754-1760.

Li, J., Ruskey, J.A., Arnulf, I., Dauvilliers, Y., Hu, M.T.M., Hogl, B., Leblond, C.S., Zhou, S., Ambalavanan, A., Ross, J.P., Bourassa, C.V., Spiegelman, D., Laurent, S.B., Stefani, A., Charley Monaca, C., Cochen De Cock, V., Boivin, M., Ferini-Strambi, L., Plazzi, G., Antelmi, E., Young, P., Heidbreder, A., Labbe, C., Ferman, T.J., Dion, P.A., Fan, D., Desautels, A., Gagnon, J.F., Dupre, N., Fon, E.A., Montplaisir, J.Y., Boeve, B.F., Postuma, R.B., Rouleau, G.A., Ross, O.A., Gan-Or, Z., 2018. Full sequencing and haplotype analysis of MAPT in Parkinson's disease and rapid eye movement sleep behavior disorder. Mov Disord. 33(6), 1016-1020.

Mao, C.Y., Yang, J., Wang, H., Zhang, S.Y., Yang, Z.H., Luo, H.Y., Li, F., Shi, M., Liu, Y.T., Zhuang, Z.P., Du, P., Wang, Y.H., Shi, C.H., Xu, Y.M., 2017. SMPD1 variants in Chinese Han patients with sporadic Parkinson's disease. Parkinsonism Relat Disord. 34, 59-61.

McKenna, A., Hanna, M., Banks, E., Sivachenko, A., Cibulskis, K., Kernytsky, A., Garimella, K., Altshuler, D., Gabriel, S., Daly, M., DePristo, M.A., 2010. The Genome Analysis Toolkit: a MapReduce framework for analyzing next-generation DNA sequencing data. Genome Res. 20(9), 1297-1303.

O'Roak, B.J., Vives, L., Fu, W., Egertson, J.D., Stanaway, I.B., Phelps, I.G., Carvill, G., Kumar, A., Lee, C., Ankenman, K., Munson, J., Hiatt, J.B., Turner, E.H., Levy, R., O'Day, D.R., Krumm, N., Coe, B.P., Martin, B.K., Borenstein, E., Nickerson, D.A., Mefford, H.C., Doherty, D., Akey, J.M., Bernier, R., Eichler, E.E., Shendure, J., 2012. Multiplex targeted sequencing identifies recurrently mutated genes in autism spectrum disorders. Science 338(6114), 1619-1622.

Ouled Amar Bencheikh, B., Ruskey, J.A., Arnulf, I., Dauvilliers, Y., Monaca, C.C., De Cock, V.C., Gagnon, J.F., Spiegelman, D., Hu, M.T.M., Hogl, B., Stefani, A., Ferini-Strambi, L., Plazzi, G., Antelmi, E., Young, P., Heidbreder, A., Mollenhauer, B., Sixel-Doring, F., Trenkwalder, C., Oertel, W., Montplaisir, J.Y., Postuma, R.B., Rouleau, G.A., Gan-Or, Z., 2018. LRRK2 protective haplotype and full sequencing study in REM sleep behavior disorder. Parkinsonism Relat Disord. 52, 98-101. 
Postuma, R.B., Arnulf, I., Hogl, B., Iranzo, A., Miyamoto, T., Dauvilliers, Y., Oertel, W., Ju, Y.E., Puligheddu, M., Jennum, P., Pelletier, A., Wolfson, C., Leu-Semenescu, S., Frauscher, B., Miyamoto, M., Cochen De Cock, V., Unger, M.M., Stiasny-Kolster, K., Fantini, M.L., Montplaisir, J.Y., 2012. A single-question screen for rapid eye movement sleep behavior disorder: a multicenter validation study. Mov Disord. 27(7), 913-916.

Postuma, R.B., Iranzo, A., Hu, M., Hogl, B., Boeve, B.F., Manni, R., Oertel, W.H., Arnulf, I., Ferini-Strambi, L., Puligheddu, M., Antelmi, E., Cochen De Cock, V., Arnaldi, D., Mollenhauer, B., Videnovic, A., Sonka, K., Jung, K.Y., Kunz, D., Dauvilliers, Y., Provini, F., Lewis, S.J., Buskova, J., Pavlova, M., Heidbreder, A., Montplaisir, J.Y., Santamaria, J., Barber, T.R., Stefani, A., St Louis, E.K., Terzaghi, M., Janzen, A., LeuSemenescu, S., Plazzi, G., Nobili, F., Sixel-Doering, F., Dusek, P., Bes, F., Cortelli, P., Ehgoetz Martens, K., Gagnon, J.F., Gaig, C., Zucconi, M., Trenkwalder, C., Gan-Or, Z., Lo, C., Rolinski, M., Mahlknecht, P., Holzknecht, E., Boeve, A.R., Teigen, L.N., Toscano, G., Mayer, G., Morbelli, S., Dawson, B., Pelletier, A., 2019. Risk and predictors of dementia and parkinsonism in idiopathic REM sleep behaviour disorder: a multicentre study. Brain 142(3), 744-759.

Purcell, S., Neale, B., Todd-Brown, K., Thomas, L., Ferreira, M.A., Bender, D., Maller, J., Sklar, P., de Bakker, P.I., Daly, M.J., Sham, P.C., 2007. PLINK: a tool set for whole-genome association and population-based linkage analyses. Am J Hum Genet. 81(3), 559-575.

Quinn, P.J., 2014. Sphingolipid symmetry governs membrane lipid raft structure. Biochim Biophys Acta. 1838(7), 1922-1930.

Rodriguez-Pascau, L., Gort, L., Schuchman, E.H., Vilageliu, L., Grinberg, D., Chabas, A., 2009. Identification and characterization of SMPD1 mutations causing Niemann-Pick types A and B in Spanish patients. Hum Mutat. 30(7), 1117-1122.

Ross, J.P., Dupre, N., Dauvilliers, Y., Strong, S., Ambalavanan, A., Spiegelman, D., DionneLaporte, A., Pourcher, E., Langlois, M., Boivin, M., Leblond, C.S., Dion, P.A., Rouleau, G.A., Gan-Or, Z., 2016. Analysis of DNAJC13 mutations in French-Canadian/French cohort of Parkinson's disease. Neurobiol Aging 45, 212 e213-212 e217.

Schuchman, E.H., Desnick, R.J., 2017. Types A and B Niemann-Pick disease. Mol Genet Metab. 120(1-2), 27-33.

St Louis, E.K., Boeve, A.R., Boeve, B.F., 2017. REM Sleep Behavior Disorder in Parkinson's Disease and Other Synucleinopathies. Mov Disord. 32(5), 645-658.

Vanier, M.T., Ferlinz, K., Rousson, R., Duthel, S., Louisot, P., Sandhoff, K., Suzuki, K., 1993. Deletion of arginine (608) in acid sphingomyelinase is the prevalent mutation among Niemann-Pick disease type B patients from northern Africa. Hum Genet. 92(4), 325-330.

Wang, K., Li, M., Hakonarson, H., 2010. ANNOVAR: functional annotation of genetic variants from high-throughput sequencing data. Nucleic Acids Res. 38(16), e164. 
Wasserstein, M.P., Schuchman, E.H., 1993. Acid Sphingomyelinase Deficiency, in: Adam, M.P., Ardinger, H.H., Pagon, R.A., Wallace, S.E., Bean, L.J.H., Stephens, K., Amemiya, A. (Eds.), GeneReviews((R)). Seattle (WA).

Zampieri, S., Filocamo, M., Pianta, A., Lualdi, S., Gort, L., Coll, M.J., Sinnott, R., Geberhiwot, T., Bembi, B., Dardis, A., 2016. SMPD1 Mutation Update: Database and Comprehensive Analysis of Published and Novel Variants. Hum Mutat. 37(2), 139-147. 
medRxiv preprint doi: https://doi.org/10.1101/2020.02.15.20023374; this version posted February 18, 2020. The copyright holder for this preprint (which was not certified by peer review) is the author/funder, who has granted medRxiv a license to display the preprint in perpetuity.

It is made available under a CC-BY 4.0 International license.

Tables

Table 1 Association of common variants in SMPD1 with risk for RBD.

\begin{tabular}{|c|c|c|c|}
\hline dbSNP & & rs1050239 & rs8164 \\
\hline Position & & $11: 6415463$ & $11: 6415882$ \\
\hline \multirow[t]{2}{*}{ Variant } & & NM_000543:c.1522G>A:p.Gly508Arg & NM_000543:c.*45G>A \\
\hline & & $\mathbf{N}(\%)$ & $\mathbf{N}(\%)$ \\
\hline \multirow[t]{3}{*}{ RBD (N=959) } & Homozygous & $49(5.11)$ & $27(2.82)$ \\
\hline & Heterozygous & $324(33.79)$ & $239(24.92)$ \\
\hline & WT & $586(61.11)$ & $693(72.26)$ \\
\hline \multirow[t]{3}{*}{ Controls $(\mathrm{N}=1287)$} & Homozygous & $50(3.89)$ & $26(2.02)$ \\
\hline & Heterozygous & $446(34.65)$ & $323(25.10)$ \\
\hline & WT & $791(61.46)$ & $938(72.88)$ \\
\hline OR $(95 \% \mathrm{CI})_{\mathrm{a}}$ & & $1.06(0.90-1.24)$ & $1.06(0.88-1.27)$ \\
\hline$p$ valuea & & 0.4778 & 0.553 \\
\hline
\end{tabular}

CI, confidence interval; GnomAD, Genome Aggregation Database; MAF, minor allele frequency; N, number; OR, odds ratio; UTR, untranslated region; WT, wild-type; RBD, Rapid eye movement sleep behavior disorder.

a Logistic regression, additive model, adjusted for age and sex. 
Table 2. Rare nonsynonymous variants and deletions detected in RBD and controls.

\begin{tabular}{|c|c|c|c|c|c|c|}
\hline Position & dbSNP & $\begin{array}{c}\text { Nucleoti } \\
\text { de } \\
\text { change }\end{array}$ & Amino acid change & $\begin{array}{c}\text { RBD } \\
(\mathbf{N}=959)\end{array}$ & $\begin{array}{c}\text { Control } \\
(\mathrm{N}=1287)\end{array}$ & $\begin{array}{c}\text { gnomAD MAF } \\
\text { (Non-Finnish } \\
\text { Europeans) }\end{array}$ \\
\hline 11:6412055 & & $\mathrm{T} / \mathrm{C}$ & NM_000534:p.Ile76Thr & 0 & $1(0.08 \%)$ & 0 \\
\hline 11:6413013 & & $\mathrm{C} / \mathrm{T}$ & NM_000534:p.Arg240Trp & $1(0.10 \%)$ & 0 & 0 \\
\hline 11:6413367 & & $\mathrm{G} / \mathrm{A}$ & NM_000534:p.Glu358Lys & $1(0.10 \%)$ & 0 & $1.80 \mathrm{E}-05$ \\
\hline 11:6413167 & rs 1803161 & $\mathrm{G} / \mathrm{A}$ & NM_000534:p.Arg291His & $2(0.21 \%)$ & $2(0.16 \%)$ & $2.20 \mathrm{E}-03$ \\
\hline 11:6413182 & rs 35824453 & $\mathrm{G} / \mathrm{A}$ & NM_000534:p.Arg296Gln & $1(0.10 \%)$ & $1(0.08 \%)$ & $1.00 \mathrm{E}-04$ \\
\hline 11:6414489 & & $\mathrm{C} / \mathrm{T}$ & NM_000534:p.Leu379Phe & 0 & $1(0.08 \%)$ & $6.67 \mathrm{E}-05$ \\
\hline $11: 6415245$ & rs141641266 & $\mathrm{C} / \mathrm{T}$ & NM_000534:p.Ala487Val & $8(0.83 \%)$ & $3(0.23 \%)$ & 4.10E-03 \\
\hline $11: 6415766$ & rs120074118 & $\mathrm{TGCC} / \mathrm{T}$ & NP_000534.3:p.Arg610del & $1(0.10 \%)$ & $1(0.08 \%)$ & $2.00 \mathrm{E}-04$ \\
\hline Total & & & & $14(1.46 \%)$ & $9(0.70 \%)$ & \\
\hline
\end{tabular}

RBD, Rapid eye movement sleep behavior disorder; GnomAD, Genome Aggregation Database; MAF, minor allele frequency; $\mathrm{N}$, number 